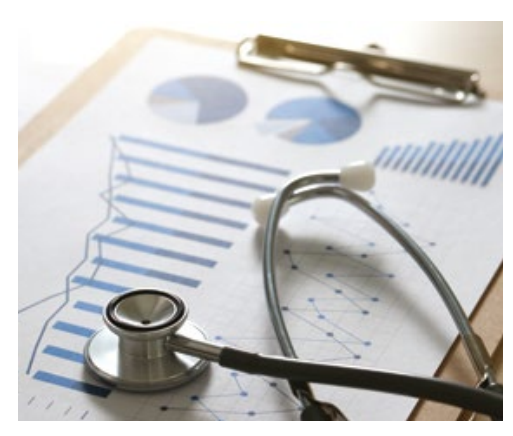

CPD

Claire Jackson, Lauren Ball

\section{Background}

Continuity of care is a fundamental element of traditional general practice linked, via an expanding evidence base, with important patient and system outcomes. It is of particular importance as populations age and live increasingly with significant, ongoing lifestyle and chronic disease challenges.

\section{Objectives}

The aim of this article is to examine the challenges in measuring and promoting continuity of care in Australia.

\section{Discussion}

Appropriate measurement is challenging and the choice of tool requires careful consideration. This should include scope, length, validation testing, accessibility of the tool, alignment with the initiative requiring evaluation, and application to local and system-level analysis. As our healthcare system looks to major reform in the near future, we must ensure that it supports and incentivises continuity of care in its policy development, care models, payment method, training, data analytics, and community consultation and messaging.

\title{
Continuity of care
}

\author{
Vital, but how do we measure and promote it?
}

CONTINUITY OF CARE has been part of general practice philosophy since inception. It is a central tenet of The Royal Australian College of General Practitioners' Quality general practice of the future, ${ }^{1}$ Royal College of General Practitioners' Promoting continuity of care in general practice, ${ }^{2}$ and the The Royal New Zealand College of General Practitioners' Aiming for excellence: The RNZCGP standard for New Zealand general practice. ${ }^{3}$ The concept underpinned Barbara Starfield's groundbreaking international work on the impact of high-quality primary care on health system outcome $\mathrm{e}^{4}$ and Julian Tudor Hart's legacy, ${ }^{5}$ and it has been jealously guarded by generations of general practitioners (GPs) and family physicians.

Despite wide support for continuity of care, there has been a steady erosion of general practice continuity of care over the past 30 years. In Australia, 34\% of very high and frequent general practice attenders see three to four GPs annually, while a further $36 \%$ see five or more. ${ }^{6}$ New models of care, such as drop-in clinics (UK, ACT) and urgent care centres in Walmart and the drugstore chain CVS (US), offer easy access, non-medical, episodic care to increasing sectors of the population. In Australia, online services, such as GP2 $\mathrm{U}^{7}$ and Qoctor, ${ }^{8}$ promote quick and inexpensive access to a one-off remote primary care encounter.

\section{Benefits of continuity of care}

Continuity of care has consistently been associated with improved outcomes, despite some variation in how the concept is defined, interpreted and assessed. Terms such as therapeutic alliance, ${ }^{9}$ working alliance, ${ }^{10}$ continuity of care,${ }^{11}$ relational continuity ${ }^{12}$ and relationshipbased care ${ }^{13}$ are fundamentally synonymous and refer to the positive outcomes that occur when a patient has an ongoing sense of affiliation, collaboration and trust with a single provider. ${ }^{14} \mathrm{High}$ levels of continuity of care (and other similar terms) have been shown to result in positive patient experiences, greater patient satisfaction, increased treatment adherence and improved patient outcomes..$^{9,10,15}$ A recent data linkage project identified continuity of care as a predictor for improved health outcomes, especially - and not surprisingly - for ambulatory-care sensitive conditions for older patients. ${ }^{16}$ Furthermore, van Loenen's recent systematic review on organisational aspects of primary care related to avoidable hospitalisation identified adequate physician supply and better longitudinal continuity of care as key influences on avoidable hospitalisation. ${ }^{17}$ Periera Gray's 2018 systematic review links increased continuity of care with lower mortality. ${ }^{18}$

Recently, two key health services studies have explored the benefits of continuity of care to patients and health systems. Last year, the Health Foundation (UK) conducted a cross-sectional study examining the association of continuity of care and hospital admission. ${ }^{16}$ Higher continuity of care was associated with $12.49 \%$ (95\% confidence intervals: $9.45,19.29)$ fewer hospital admissions, 
compared with patients with low continuity of care. ${ }^{16}$ Data from an ongoing cohort study in older people in the Netherlands (the Longitudinal Aging Study Amsterdam) showed a low level of continuity of care to be associated with a higher risk of mortality. ${ }^{19}$ These large studies support the development of care models that improve continuity of care.

A stronger focus on continuity of care in contemporary care delivery is therefore clearly warranted. With a growing number of Australians who have high health and social care needs, and community pressure to better support them, continuity of care is increasingly a critical reform element for our Council of Australian Governments.

\section{The challenge of measuring continuity of care}

If we wish to encourage and evaluate the effect of care continuity, we must use effective measures. Most largescale studies, such as those above, use formulaic indices to measure and quantify continuity of care, enabling a numerical score to be computed for individual patients on the basis of the consistency of providers they have encountered over a given time. This approach allows large-scale statistical analysis with other quantifiable outcomes, at the level of the individual, provider and service. However, formulaic indices have limitations, chiefly, the inability to capture the experiential and humanistic nature of high-quality relationships between patients and providers. ${ }^{20}$ Exploring continuity of care using qualitative approaches provides a richer understanding of the connection between patients and primary care providers, ${ }^{20}$ but currently does not enable the 'big data' analyses stated above.

Finding the all-important measurement 'balance' was the focus of a recent systematic review (LB, Kate Barnes, Lisa Crossland, Caroline Nicholson, CJ, unpublished data) exploring tools that were considered strongest candidates to address this conundrum. The authors searched for existing tools that went beyond formulaic indices to capture information about the depth of the relationship between patients and providers. No qualitative tools were found, but three quantitative questionnaires were identified as coming closest to bridging the evidence gap. These questionnaires - Care Continuity Across Levels of Care Scale, ${ }^{21}$ the Nijmegan Continuity Questionnaire ${ }^{22}$ and the Patient-Doctor Depth of Relationship Tool, ${ }^{23}$ - were freely available in English and did not require additional pilot work prior to use. ${ }^{19}$ Ongoing work in the area may benefit from their inclusion. Choice of tool requires careful consideration, including the scope, length, validation testing, accessibility of the tool and alignment with the initiative being evaluated. The ongoing challenge, as the area develops, will be to use valid, brief, but comprehensive, assessments of continuity of care that enable both local and system-level analysis.

\section{The challenge for Australia}

If we are convinced of its importance, and can measure its application and impact, how do we encourage uptake of continuity of care by community members, clinicians and policymakers?

\section{Culture change}

Our historic approach to primary care delivery has prioritised access and universal choice. Yet, the literature increasingly argues that continuity is a safer and more satisfying metric for the many Australians with ongoing conditions. We need to share the evidence with our patients and communities, allowing them to make informed choices of the best care to suit their individual circumstances. Better including them in discussions, and understanding their needs and expectations in embracing the concept, is essential.

\section{Models of care}

New care models, such as the PatientCentred Medical Home (US), Primary Care Home (UK) and Health Care Home (Australia), promote both continuity and accountability at their core. Thus, effective measures of continuity of care and assessment of impact on key quality, satisfaction and efficiency metrics are essential.

\section{Incentives}

Our current general practice funding model most strongly rewards recurrent standard face-to-face consultations, with negligible reward to either patient or practice for continuity or virtual care. Facilitating encounters that are not faceto-face will be essential for true care continuity, especially with groups that are hard to reach. Reform workgroups such as the Medicare Benefit Schedule Review Taskforce should consider appropriate continuity of care incentives for patients and practices to incentivise ongoing support, accountability and engagement. This could include patient benefits such as enhanced in-hour, after-hour or electronic access for voluntary practice linkage, and practice and practitioner incentives such as 'year of care' payment for prevention, chronic disease management and hospital avoidance. Practice Incentive Program payments could support informational continuity, care coordination and clinical quality metrics, with supplementary support payments linked with age, social disadvantage and rurality.

\section{Training}

The impact of continuity of care and relational continuity on care outcome and satisfaction should be part of every college's future training curriculum. With population care now so weighted to complex chronic disease, frailty, and social and mental health support, our entire health community must be involved in better understanding and fostering its uptake.

\section{Continuity with whom?}

Much of our continuity of care focus to date has been on the relationship between the patient, family and their practice or primary care clinician. Yet the most complex patients increasingly require support more broadly to maintain optimal health status. This appropriately raises the input of the 'medical community' or 'medical village' in ongoing care 
relationships. This concept links the secondary and tertiary care sector more closely with the patient's practice, shared care planning and community care team, and again highlights the importance of informational continuity of care at all service delivery points.

\section{Conclusion}

Continuity of care is a fundamental element of traditional general practice, increasingly linked with important patient and system effects. It is of growing importance as our populations age and live increasingly with significant, ongoing lifestyle and chronic disease challenges. As our healthcare system looks to major reform in the near future, we must ensure that it supports and incentivises continuity of care in its policy development, care models, payment method, training, data analytics, and community consultation and messaging.

\section{Authors}

Claire Jackson MBBS, MD, MPH, CertHEcon, GradCert Management, FRACGP, FAICD Professor in General Practice and Primary Health Care Research, University of Qld, Primary Care Clinical Unit, Faculty of Medicine, Brisbane, Qld; Director, Centres for Health Care Reform and Integration, University of Qld, Mater Hospital, Brisbane, Qld; Independent Director, Hospitals Contribution Fund of Australia; Chair, biennial International Primary Health Care Reform Conference, Australia; Sessional GP, Camp Hill Health Centre, Brisbane, Qld.c.jackson@uq.edu.au

Lauren Ball PhD, MNutrDiet, GCertHigherEd, BAppSc, NHMRC and Senior Research Fellow, Menzies Health Institute Queensland, Griffith University, Gold Coast, Qld; Visiting Senior Research Fellow, Centre for Health System Reform and Integration, UQ-Mater Research Institute, Brisbane, Qld

Competing interests: None.

Funding: None.

Provenance and peer review: Commissioned, externally peer reviewed.

\section{References}

1. Royal Australian College of General Practitioners (RACGP). A quality general practice of the future: The RACGP presidential task force on health reform. East Melbourne: RACGP, 2012 Available at www.racgp.org.au/support/policies/ health-systems-and-environmental [Accessed 23 April 2018].

2. Royal College of General Practitioners (RCGP). Promoting continuity of care in general practice: Summary paper. RCGP: London, 2011. Available at www.drsharmaspractice. co.uk/mf.ashx?ID=6b6f6fbb-a298-467d-92eb74d888ea496e [Accessed 23 April 2018].
3. Royal New Zealand College of General Practitioners (RNZCGP). Aiming for Excellence: The RNZCGP standard for New Zealand general practice. For Foundation and CORNERSTONE ${ }^{\circledR}$ practices. Wellington: RNZCGP, 2016. Available at https://oldgp16.rnzcgp.org.nz/assets/ New-website/Quality/Aiming-for-Excellence-20Sept-2016-FINAL.pdf [Accessed 23 April 2018].

4. Starfield B, Shi L, Macinko J. Contribution of primary care to health systems and health. Milbank Q 2005;83(3):457-502. doi: 10.1111/j.14680009.2005.00409.x

5. Watt G, O'Donnell C, Sridharan S. Building on Julian Tudor Hart's example of anticipatory care. Prim Health Care Res Dev 12(1):3-10. doi: 10.1017/ S1463423610000216.

6. Australian Institute of Health and Welfare. Healthy communities: Frequent GP attenders and their use of health services in 2012-13. Sydney: My Healthy Communities, 2015

7. GP2U. Case studies - Online doctors in action. Tasmania: GP2U, 2018. Available at https://gp2u. com.au [Accessed 23 April 2018].

8. Qoctor. Qoctor, your quick, online doctor. Melbourne: Qoctor, 2018. Available at www.qoctor. com.au [Accessed 23 April 2018].

9. Martin D, Garske J, Davis M. Relation of the therapeutic alliance with outcome and other variables: A meta-analytic review. J Consult Clin Psychol 2000;68(3):438-50.

10. Fuertes J, Mislowack A, Bennett J. The physicianpatient working alliance. Patient Educ Couns 2007;66(1):29-36. doi: 10.1016/j.pec.2006.09.013.

11. Alazri M, Heywood P, Neal R, Leese B. Continuity of care: Literature review and implications. Sultan Qaboos Univ Med J 2007;7(3):197-206.

12. Kristjansson E, Hogg W, Dahrouge S, Tuna M, Mayo-Bruisma L, Gebremichael G. Predictors of relational continuity in primary care: Patient, provider and practice factors. BMC Fam Pract 2013;14:72. doi: 10.1186/1471-2296-14-72.

13. Koloroutis M, Manthey M, Felgen J, et al. Relationship-based care: A model for transforming practice. USA: Creative Health Care Management, 2007.

14. Scott J, Cohen D, DiCicco-Bloom B, Miller W, Stange K, Crabtree B. Understanding healing relationships in primary care. Ann Fam Med 2008;6(4):315-22. doi: 10.1370/afm.860.

15. Griffith S. A review of the factors associated with patient compliance and the taking of prescribed medicines. Br J Gen Pract 1990;40(332):114-16.

16. Barker I, Steventon A, Deeny S. Association between continuity of care in general practice and hospital admissions for ambulatory care sensitive conditions: Cross sectional study of routinely collected, person level data. BMJ 2017;356:j84. doi: 10.1136/bmj.j84.

17. van Loenen $T$, van den Berg M, Westert G, Faber M. Organizational aspects of primary care related to avoidable hospitalization: A systematic review. Fam Pract 2014;31(5):502-16. doi: 10.1093/ fampra/cmu053.

18. Periera Gray D, Sidaway-Lee K, White E, Thorne A, Evans PH. Continuity of care with doctors - A matter of life and death? A systematic review of continuity of care and mortality. BMJ Open 2018;8(6):e021161. doi: 10.1136/bmjopen-2017021161.
19. Maarsingh O, Henry Y, van de Ven P, Deeg D. Continuity of care in primary care and association with survival in older people: A 17-year prospective cohort study. Br J Gen Pract 2016;66(649):e531-39. doi: 10.3399/bjgp16X686101.

20. Haggerty J, Roberge D, Freeman G, Beaulieu C. Experienced continuity of care when patients see multiple clinicians: A qualitative metasummary. Ann Fam Med 2013;11(3):262-71. doi: 10.1370/ afm.1499.

21. Aller M, Vargas I, Garcia-Subirats I, et al. A tool for assessing continuity of care across care levels: An extended psychometric validation of the CCAENA questionnaire. Int J Integr Care 2013;13:e050.

22. Uijen A, Schers $H$, Schellevis FG, Mokkink HG, van Weel $C$, van den Bosch WJ. Measuring continuity of care: Psychometric properties of the Nijmegen Continuity Questionnaire. Br J Gen Pract 2012;62(600):e949-57. doi: 10.3399/ bjgp12X652364.

23. Ridd M, Lewis G, Peters T, Salisbury C. Patientdoctor depth-of-relationship scale: Development and validation. Ann Fam Med 2011;9(6):538-45. doi: $10.1370 /$ afm.1322. 